\title{
4 \\ La figura del Consejero independiente en el Gobierno Corporativo de las Cooperativas
}

Premio AIDC. 2004

\author{
Edurne Isasmendi Melgar \\ Lda. en Derecho por la Universidad del País Vasco. \\ Máster en Abogacía de Empresa, Universidad del País Vasco e \\ llustre Colegio de Abogados de Guipúzcoa.
}

\section{Agradecimientos}

Quiero manifestar aquí mi sincero agradecimiento a todas las personas y Empresas Cooperativas que me han ayudado y dedicado su tiempo, ya que sin ellas no hubiera sido posible elaborar este trabajo.

En concreto, quisiera destacar la ayuda prestada por el Instituto de Estudios Cooperativos «Lanki» y al Grupo M.C.C especialmente a D. Adrián Zelaia, Secretario del Consejo Rector.

Finalmente, expresar mi reconocimiento y gratitud a la labor de tutorización desempeñada por el profesor Dr. D. Alberto Emparanza Sobejano, Profesor Titular de Derecho Mercantil de la Universidad del País Vasco UPV-EHU.

Sumario: I. Introducción. II. El Consejo Rector.-III. Consejeros independientes: el Consejero independiente en el Corporate Governance. 1. Planteamiento. 2. El Consejo independiente.-IV. Estatuto Jurídico del Consejero Independiente. 3. Composición. 4. Nombramiento. 5. Función. 6. Responsabilidad.-V. Los Consejeros independientes o no socios en las Sociedades Cooperativas. 1. Situación del Consejero Independiente en los grupos de Cooperativas. 2. Régimen legal. 3. Los beneficios de implantar la figura del Consejero Independiente en las Cooperativas.-VI. Conclusiones. 


\section{Introducción}

1. El presente trabajo pretende acercar y dar a conocer la existencia de una valiosa figura como es la del Consejero Independiente al Gobierno Corporativo de las Sociedades Cooperativas. Deseamos recomendar e incentivar la inclusión de esta figura en el órgano de gobierno de las Cooperativas como si fuera un miembro más de la misma.

2. Con este propósito, nuestro trabajo se centrará en el análisis del Gobierno Corporativo de las Sociedades Cooperativas en materia de estructura orgánica, más concretamente, profundizaremos en el estudio de la posibilidad de que puedan llegar a ser nombrados Consejeros, sujetos que no revisten la condición de socios, o también conocidos como "consejeros externos independientes»

Este trabajo no desea mantenerse únicamente en un ámbito teórico, siendo esto así, hemos querido conocer algunas Cooperativas de cerca y por ello hemos estimado oportuno, realizar un pequeño pero, a su vez, beneficioso estudio de campo, mediante una serie de entrevistas a personas expertas en materia de Cooperativas, con el objetivo de poder palpar cuál es el funcionamiento en la práctica de estas sociedades y obtener una información más detallada y precisa.

3. En cuanto a la estructura del contenido de este estudio, se realizará de la siguiente manera; primeramente, nos centraremos de modo general y sin entrar en detalles, en el análisis del órgano de gobierno de las Sociedades Cooperativas, denominado Consejo Rector. Posteriormente, nos detendremos en el estudio de los Consejeros Independientes, figura clave de nuestro trabajo. Finalmente, se tratará de ponderar la posible inserción de esta figura en el seno de las Sociedades Cooperativas.

\section{El Consejo Rector}

1. Cuando se habla de la administración y representación de las Sociedades Cooperativas, nos estamos refiriendo al llamado Consejo Rector. Podemos afirmar que el Consejo Rector es el órgano máximo de las Cooperativas, y que junto a la Asamblea General, es el órgano que constituye el gobierno de estas sociedades. 
Dicho esto, a continuación, desarrollaremos de forma general, sin entrar en muchas precisiones, los aspectos más relevantes de este órgano con el fin de conocer más de cerca esta importante figura. Para este estudio utilizaremos tanto el articulado de la Ley Estatal, denominada Ley General de Cooperativas 27/1999 como la Ley de la Comunidad Autónoma del País Vasco, Ley de Cooperativas de Euskadi 4/1993, puesto que es éste el marco legal donde se mueven los órganos sociales de las Sociedades Cooperativas.

2. Primeramente, empezaremos por definirlo como el órgano colegiado de gobierno de las Sociedades Cooperativas, al que corresponde, como funciones exclusivas, la de gobierno, gestión y representación de la Cooperativa y las demás que le sean atribuidas por ley o por los Estatutos ${ }^{1}$.

Se le denomina, o toma el nombre de Consejo Rector cuando lo componen más de un miembro, esto es, cuando los administradores se configuran como un órgano colegiado. Aun así, si los estatutos lo recogen, cabe en las Cooperativas de hasta diez socios, tener un Administrador Unico, el cual, eso sí, tendrá que ser socio. La razón de este último matiz, concretamente se debe a que, tanto la LGC en su artículo 34.2 como la LCE en el artículo 41.2 bajo el título, La Elección, permiten que parte de los miembros que componen el Consejo puedan no ser socios.

3. Ya que hemos mencionado los artículos que regulan la elección de los administradores o consejeros, conviene señalar que es la Asamblea General quien tiene la competencia para nombrar o elegir a los miembros del Consejo Rector, en votación secreta y mediante el mayor número de votos válidamente emitidos².

Siguiendo con el análisis de la composición de este órgano, podemos decir que respecto al número de consejeros serán los Estatutos de cada sociedad quienes lo establezcan, del mismo modo que, en lo que se refiere a la duración del mandato, el funcionamiento,... Observando las leyes citadas, la Estatal recoge, que el número de consejeros será entre tres y quince (artículo 33); en cambio en la LCE, como la

1 Así lo establece el artículo 32 Ley General de Cooperativas, en adelante, «LGC»y el artículo 40 en la Ley de Cooperativas de Euskadi, en adelante, «LCE», al hablarnos de su naturaleza y competencias.

2 Así lo atribuyen los artículo 34 LGC y artículo, 41 LCE. 
mayoría de las leyes autonómicas, solo establece un mínimo³ ${ }^{3}$ como lo hace el artículo 45 que lo regula literalmente al decir que no podrá ser inferior a tres consejeros.

Es obvio, que dentro del Consejo es necesaria la existencia de las figuras del Presidente, figura relevante en el seno de la Cooperativa, y la del Secretario. En cuanto a la elección de estos cargos se cede de nuevo a lo contemplado en los Estatutos, por lo que, salvo disposición contraria, será el mismo Consejo Rector quien elija entre sus miembros los cargos de Presidente y Secretario.

4. Continuando con los consejeros o administradores, podemos observar respecto a la capacidad para ser consejero, que las Leyes Cooperativas contemplan la incapacidad y prohibiciones por las cuales los administradores o consejeros no podrán desempeñar sus funciones ni ejercer como tal.

Concretamente, la LGC, con carácter común para el órgano de Intervención ${ }^{4}$, establece en el artículo 41, una relación de incompatibilidades, incapacidades y prohibiciones, regulando en diferentes apartados las causas concretas. Además, hay que precisar que la LGC especifica, a diferencia de la LCE, la prohibición del desempeño de cargos de aquel órgano en más de tres cooperativas de primer grado, simultáneamente. Igualmente, en lo que a la LCE se refiere, establece, mediante un listado los sujetos que no podrán ser administradores. artículo 42 señala literalmente: Los quebrados y concursados no rehabilitados, los menores e incapacitados, ... b) los funcionarios y personal al servicio de la Administración, con funciones a su cargo que se relacionen con las actividades propias de la cooperativa de que se trate. c) los que desempeñen o ejerzan por cuenta propia o ajena actividades competitivas a las de la cooperativa... d) los miembros de la Comisión de Vigilancia y del Comité de Recursos y los directores-gerentes. e) los incursos en los supuestos estatutariamente previstos. Este precepto, en su apartado segundo, establece que los administradores inmersos en estos supuestos deberán cesar del cargo.

5. La concurrencia de alguna de estas situaciones o causas citadas (incompatibilidad, incapacidad, prohibiciones) son motivo de término

3 Lo exponen, M. ${ }^{\text {a }}$ José Morillas Jarillo y Manuel Ignacio Feliú ReY en Curso de Cooperativa. Editorial Tecnos. Madrid 2002. p. 292.

4 Es el órgano de fiscalización interno de las Cooperativas, Morillas Jarillo y Feliú REY, op. cit., pp. 343 y ss. 
del mandato. Otra de las causas para la conclusión del nombramiento como consejero, es el transcurso del tiempo para el cual fueron elegidos dichos sujetos, esto es, el transcurso del plazo del mandato. Este periodo se fijará en los Estatutos, en general, la duración suele ser entre dos y seis años, aun así la LGC cita que será entre tres y seis ${ }^{5}$.

6. Otro aspecto que afecta a los consejeros es el de la remuneración, que lo prevé tanto la LGC como LCE. Los Estatutos o la Asamblea General podrán regular este aspecto, tanto en lo que se refiere al derecho de retribución como a la cuantía. En todo caso, los gastos ocasionados por el cargo se pagarán siempre, así lo contiene o regula el artículo 43 de la Ley autonómica. La Ley Estatal, en cambio, difiere de aquélla en cuanto que, establece la retribución para los denominados Consejeros Independientes o los no socios, eso sí, de igual modo, en lo que se refiere a los socios estos no serán retribuidos pero sí compensados por los gastos que origine su función.

7. En cuanto al funcionamiento del Consejo Rector, como hemos apuntado anteriormente, hay potestad autorreguladora, esto quiere decir que se encuentra regulado en los Estatutos y en lo no previsto decidirá el propio Consejo Rector.

Quien ostente el cargo de presidente se encargará de realizar la convocatoria del Consejo. Según lo que apuntan tanto los artículos 36 LGC como el artículo 46 LCE, las sesiones se celebrarán cuando asista más de la mitad de sus miembros.

De igual modo, por más de la mitad de los votos de los asistentes, se adoptarán los acuerdos, que en caso de empate será el presidente quien lo resuelva mediante su voto.

Estos acuerdos serán llevados al libro de actas, también se ha de recoger en dicho libro el debate y el resultado de las votaciones.

8. Por último, para concluir con este escueto análisis sobre este órgano, citaremos el régimen jurídico de la responsabilidad de los administradores. El Consejo Rector deberá actuar como un ordenado empresario y representante leal, de buena fe ..., respondiendo por los daños que ocasionen por actos contrarios a la Ley y Estatutos. Esta responsabilidad será siempre solidaria. Debemos destacar que la LGC en su artículo 43, realiza una remisión a la Ley de Sociedades Anóni-

5 En cuanto a la duración véase artículo 35 LGC y artículo 44 LCE. 
mas, rigiéndose así la responsabilidad de los administradores o consejeros de las Cooperativas, de igual modo que lo dispuesto para los de las Sociedades Anónimas. Se entiende también incluida en esta remisión, lo referente al estándar de diligencia previsto para estos consejeros, puesto que el precepto 43 no lo establece expresamente ${ }^{6}$. Cabe citar que esta materia, al igual que ocurre con las retribuciones artículo 40, o como señalamos en lo referente a las incompatibilidades, incapacidades y prohibiciones artículo 41 , se regula en las disposiciones comunes de la Intervención. Por otro lado, si observamos la LCE, podemos percatarnos de la particularidad que plantea el artículo 47, precisamente la contemplación de una mayor responsabilidad en el caso de que el cargo percibiese alguna retribución.

Una vez analizado de forma general el Consejo Rector de las Sociedades Cooperativas, seguidamente nos centraremos y profundizaremos en el estudio de los sujetos que forman o que pueden formar parte de este órgano. Concretamente, de entre los miembros que lo constituyen, examinaremos exclusivamente la figura que lleva por nombre Consejero Independiente.

\section{El Consejero Independiente en el Corporate Governance}

\section{Planteamiento}

1. Como señaló en su día el Informe Británico Cadbury, El gobierno corporativo es el sistema mediante el cual se dirigen y controlan las sociedades; se trata, por tanto, de un conjunto de reglas e instituciones que determinan cómo se conducen, dirigen y administran las empresas. La importancia del Ilamado Gobierno Corporativo o en términos anglosajones lo que se conoce por Corporate Governance, radica en la contribución a la prosperidad de la sociedad, lo que significa, en otros términos, que ha de estar orientado por el bien de la empresa y por su continuidad.

6 Los autores MoRILLAS JARILlo y Feliú ReY, han tachado la remisión de desafortunada, op. cit., pp. 329 y ss, en el mismo sentido, Sequeira Martín y SACRISTÁn Bengia, véase el informe: Una reflexión sobre la responsabilidad de los miembros del Consejo Rector de las Cooperativas. Revista de Derecho de Sociedades. núm. 21 2003-2.

7 Informe del comité sobre los aspectos financieros del Gobierno Corporativo. Diciembre de 1992. 
2. Surgen muchas controversias cuando hablamos del gobierno corporativo, y muchas de esas discusiones están centradas en el funcionamiento de los Consejos de Administración. Con el objetivo de mitigar esas diferencias, se han venido realizando los denominados «Códigos o Informes Éticos o también conocidos como de Buen Gobierno».

En el Estado Español nos encontramos con dos informes. El pionero fue el llamado «Código Olivencia» del año $1998^{8}$ y más recientemente se ha elaborado el "Informe Aldama» ${ }^{9}$. Las recomendaciones de estos códigos tienen por objeto plantear soluciones a los problemas surgidos en la estructura de los órganos de administración de las sociedades e impulsar la profesionalización, transparencia y eficacia de los consejos y también de cada uno de los consejeros. Concretamente, esta es la idea que subraya el Código Olivencia.

Los destinatarios de estos códigos, son en primer lugar y fundamentalmente las Sociedades Cotizadas. Aun así no se excluye la posibilidad de que otras sociedades de diferente naturaleza a éstas, puedan adoptar las recomendaciones que en estos documentos se contienen, con el fin de mejorar así sus estructuras de gobierno. A nuestro entender, cabría la posibilidad de implantar estos códigos en las Sociedades Cooperativas, pero éste no es el estudio que hoy nos ocupa, por tanto dejaremos este debate para una próxima ocasión ${ }^{10}$.

\section{El Consejero Independiente}

1. Los Consejeros Independientes son una de las principales señas de identidad del Gobierno Corporativo o Corporate Governance en lo

8 Código Olivencia: elaborado por la Comisión Especial para el estudio de un código ético de los consejeros de administración de las Sociedades Cotizadas de 26 de febrero de 1998.

9 Informe Aldama: Informe de la Comisión Especial para el Fomento de la transparencia y seguridad en los mercados y en las Sociedades Cotizadas, publicado el 8 de enero de 2003.

10 * Hemos querido saber la opinión que les merece, a los expertos entrevistados, los Códigos de Buen Gobierno. En este sentido la idea general recogida es la siguiente: Los valoran como instrumentos interesantes, pero a su vez manifiestan su complejidad. Ven unos códigos muy específicos dirigidos a las Sociedades Cotizadas en concreto. A juicio de los entrevistados no cabe trasladar estos códigos analógicamente al ámbito de las Sociedades Cooperativas, puesto que deben ajustarse y adaptarse a las condiciones de cada tipo de Cooperativas. Ahora bien, en cierta medida las Cooperativas, utilizan herramientas similares o equiparables a estos códigos. Por ejemplo hablan sobre «reglamentos de juntas» o de « informes específicos»... 
que se refiere a su estructura. Ultimamente la articulación orgánica del Organo de Administración, se ha planteado como una de las mayores dificultades del sistema de gobierno de las sociedades, especialmente, en las sociedades cotizadas. A modo de síntesis y para un mejor reequilibrio del Consejo, se ha propuesto el nombramiento de Administradores o Consejeros Independientes. Más aún, debemos resaltar, que entre las recomendaciones sugeridas por una mejora del Gobierno Corporativo, nos encontramos la de potenciar la figura del Consejero Independiente.

2. Particular interés suscita este sujeto, a los Códigos o Informes de Buen Gobierno anteriormente ya mencionados, ya que recalcan el papel central y fundamental de estos Consejeros. Conviene destacar, en este sentido, que dichos informes señalan entre sus recomendaciones la integración de esta figura en los Consejos de Administración. En concreto, dicha integración de los denominados Consejeros Independientes, se fundamenta en incorporar en el órgano de gobierno, personalidades desvinculadas del equipo de gestión; pues bien, estos sujetos deberán de cumplir ciertos requisitos, tales como, gozar de una notable cualificación profesional, ostentar una indudable neutralidad a la hora de la toma de decisiones, ser independiente del resto de miembros del Consejo, etc.

\section{Estatuto Jurídico del Consejero Independiente}

A continuación, mediante el análisis del estatuto jurídico, determinaremos el contenido y su posición jurídica, con el objetivo de conocer, con más detalle, las peculiaridades de esta figura.

\section{Composición}

1. El Consejo de Administración, o para el caso de las Sociedades Cooperativas, más conocido como Consejo Rector, se compone de diferentes clases o grupos de consejeros. Entre ellos podemos distinguir, en primer lugar, los Consejeros internos o ejecutivos: los cuales, como el propio nombre indica, poseen funciones ejecutivas o directivas, y por otro lado, los Consejeros externos, distinguiéndose estos, entre los Dominicales y los propiamente Independientes. Para nuestro campo de estudio nos centraremos únicamente en estos últimos.

2. Como bien ha quedado reflejado, la figura del Consejero Independiente ostenta un destacado lugar en los Códigos Éticos o de 
Buen Gobierno. Precisamente son estos códigos, los que plantean expresamente la fijación de una determinada proporción con relación a la composición. Aconsejan, que los Consejeros externos representen la mayoría de los miembros del Consejo; más aún, dentro de este grupo, se subraya que exista una participación significativa de los denominados

Consejeros Independientes, sin que ello elimine el equilibrio que se debe mantener entre los diferentes tipos de consejeros externos, como hemos señalado hace poco, catalogados como dominicales e independientes.

La finalidad de esta recomendación es garantizar un control por parte de personas independientes, tratando, en definitiva, de evitar que la toma de decisiones dentro del órgano, se concentren en una persona o grupo de personas. Por tanto los Códigos de Buen Gobierno acentúan esta propuesta, con el fin de que los consejeros externos tengan peso en las decisiones a tomar dentro del Consejo.

3. En este sentido, consideramos oportuno y de gran ayuda traer literalmente los números dos y tres, de las veintitrés recomendaciones que minuciosamente contiene el Informe del Código Olivencia, que dicen así: (Rec.2) «Que se integre en el Consejo de Administración un número razonable de consejeros independientes, cuyo perfil responda a personas de prestigio profesional desvinculadas del equipo ejecutivo y de los accionistas significativos». (Rec.3) «Que en la composición del Consejo de Administración los consejeros externos (dominicales e independientes) constituyan amplia mayoría sobre los ejecutivos y que la proporción entre los dominicales e independientes se establezca teniendo en cuenta la relación existente entre el capital integrado por paquetes significativos y el resto».

\section{Nombramiento}

1. El proceso de selección utilizado generalmente para el nombramiento de los Consejeros Independientes es el sistema de Cooptación ${ }^{11}$, previsto principalmente para las sociedades cotizadas ${ }^{12}$. Pero

11 Cooptar: llenar las vacantes de una corporación mediante el voto de los integrantes de la misma. Diccionario General de la Lengua Española Vox. Spes. Editorial s.l, 2002

12 Artículo 138 del mismo cuerpo legal. 
el Código Olivencia, va más allá y realiza una especial referencia a la selección de Consejeros. Este código, propone la intervención de la calificada «Comisión del Nombramiento». La finalidad o propósito de esta comisión, únicamente es, la de velar por la integridad del proceso de designación de consejeros, y asegurar así, que se cumplen los requisitos de independencia, es decir, verificar la inexistencia de vínculos con el objetivo último de conseguir una mayor transparencia. Más aun, debemos de resaltar que el código, expone una serie de indicaciones $^{13}$ con la intención de orientar adecuadamente a la comisión. Hay que dejar claro, que será el propio Consejo, quien seleccione a los consejeros, por tanto, dicha comisión no sustituirá al Consejo Rector.

\section{Función}

1. Entre las reflexiones que nos aporta, el Código Olivencia, al tratar sobre la figura del Consejero Independiente, cita la de su cometido, expresamente: ... cuya misión primordial consiste en hacer valer en el Consejo los intereses del capital flotante ${ }^{14}$. La labor a desempeñar por estos sujetos será la misma que la de sus compañeros del Consejo: deberán aconsejar y prestar servicio de igual modo, pero a esto hay que añadirle la particularidad de que se trata de un sujeto imparcial, neutral, autónomo, en definitiva, independiente. Estos Consejeros Independientes siendo miembros del Consejo de Administración no están vinculados con el equipo de gestión, es decir, no se hallan ligados a la sociedad. Concretamente ésta es la característica que les precede, y todo ello conlleva, que ejerciten sus actividades de modo objetivo e imparcial. Asegura el Informe o Código Olivencia, que la entrada de Consejeros en el órgano de gobierno incrementará su representatividad, ampliará sus puntos de vista y elevará la disposición y la capacidad del consejo para desarrollar con eficiencia la función de supervisión.

\section{Responsabilidad}

1. En cuanto a este aspecto, debemos manifestar que todos los consejeros son iguales y responden del mismo modo. Por tanto, teniendo esto en consideración, nada afecta que se distingan diferentes

13 Punto5.2 del Código de buen Gobierno.

14 Punto 2.1 del Codigo Olivencia. 
tipos de consejeros, es decir, no importa si nos encontramos ante consejeros ejecutivos o consejeros externos, y dentro de estos últimos, si son los llamados dominicales o los que nos interesan para nuestro estudio los llamados independientes. Por otra parte, tampoco tendrá relevancia, ni consecuencia alguna para esta disciplina, como es la de responsabilidad, el haber optado por configurar a los consejeros mediante determinadas proporciones. Cabe citar que esta última matización la desarrolla de igual modo en uno de sus puntos el Informe Cadbury ${ }^{15}$, uno de los códigos éticos o denominado específicamente «código de la mejor práctica», más emblemático y destacado conocido en el mundo anglosajón.

\section{Los Consejeros independientes o no socios en las Sociedades Cooperativas}

Tras el estudio, no muy exhaustivo pero sí conciso hasta ahora desarrollado sobre los calificados como Consejeros Externos Independientes, éste es el momento de adentrarnos en el fundamento propio del tema que nos ocupa.

1. Situación del Consejero Independiente en los grupos de Cooperativas

1. Generalmente, según el estudio llevado a cabo, las Sociedades Cooperativas no apuestan por la plena inserción de los denominados no socios. Las personas entrevistadas se muestran algo reacias ante la penetración de esta figura principalmente por dos motivos: por la falta de un esquema más diáfano que esclarezcan todas sus dudas; y más concretamente, por la escasez de experiencia previa en relación al nombramiento de estas personas. Consideran complicada o confusa la integración, dada la complejidad de cada una de las Cooperativas. Con esta idea, lo que se quiere señalar, es que cada Cooperativa es un mundo, es decir, existen distintos tipos o clases de Cooperativas, y cada una posee sus peculiaridades y características propias. En otras palabras, se ha de tener en consideración las diferentes especificidades de cada tipo de Cooperativa, en base a su diferente tamaño, la experiencia, o la clase de cooperativa. Teniendo esto en consideración,

15 Véase el punto 4.3 del Informe Cadbury. 
las personas entrevistadas, manifiestan que no se puede generalizar la alternativa recogida por las leyes de la posible implantación de un miembro no socio, esto es, no se puede asegurar si es buena o mala dicha integración, no hay una única respuesta. Como nos han señalado, se debe analizar cada caso en concreto, teniendo en cuenta toda singularidad antes de tomar cualquier decisión que repercuta a la sociedad.

2. Ahora bien, no ponen en duda, que nos hallamos ante una figura favorable y recomendable, puesto que aporta un nuevo knowhow, siempre propicio para toda clase de sociedad. Igualmente, resaltan la gran aportación y asesoramiento que podrían desempeñar estos no socios, proporcionando mejoras para el buen funcionamiento del Consejo Rector. Es más, en el caso de considerar el nombramiento de estos sujetos, si se les pregunta por las competencias que dichos Consejeros Independientes gozarían o por el contrario, de los límites que padecerían, no ponen obstáculo en afirmar que serían iguales, es decir, considerarían a estos consejeros de la misma forma que los demás miembros.

3. Además debemos precisar, que en el ejercicio o vida diaria de estas sociedades, aunque no se definan específicamente como Consejeros Independientes, se pueden observar figuras equivalentes o parecidas, ha dichos consejeros. Por ejemplo como alternativa, algunas Cooperativas optan por trabajadores por cuenta ajena que puedan acudir a las sesiones del Consejo Rector con voz pero sin voto; también se ha dado el caso de nombrar a personas de consultoras o de las agrupaciones, es decir, personas de reconocida cualificación. Eso sí, en general advierten que la elección de estas personas están dirigidas sólo para casos o situaciones puntuales.

4. Por otra parte, es interesante señalar la problemática que se observa dentro de las Cooperativas de Enseñanza. No es nuestro cometido describir detalladamente las dificultades registradas en esta clase de Cooperativas, pero sí creemos que merece la pena tener en cuenta aunque sea superficialmente la situación.

Primeramente, antes de entrar en materia, para situarnos, diremos que este tipo de Cooperativas, desarrollan actividades docentes en distintos niveles y modalidades, así como otras actividades complementarias. Concretamente se regulan en la LGC bajo el título «De las Cooperativas de Enseñanza» en un único articulo 103, del mismo 
modo se contempla en la LCE artículo 106 (y 107,108). Los artículos mencionados no revisten grandes complicaciones, puesto que su contenido es semejante ${ }^{19}$.

Dejando de lado las peculiaridades de estas Cooperativas, conviene señalar que la problemática advertida se debe en gran parte a la gran rotación de los miembros de los órganos, es decir, existe un flujo constante de personas, y por consiguiente, una gran falta de asentamiento dentro de los órganos. En otras palabras, por lo que a la temática aquí estudiada uno de los mayores inconvenientes de las Cooperativas de Enseñanza es la inestabilidad del Consejo, debido al constante cambio de los miembros que lo componen. El resultado, es el poco tiempo e insuficiente que estas personas tienen para una buena formación y de ahí los problemas que esto conlleva.

Personas expertas en esta materia, admiten dicha insuficiencia o carencia, y apuntan que un instrumento útil a modo de solución para evitar o prevenir conflictos y sobre todo para una mayor estabilidad, sería la de integrar los denominados Consejeros Independientes o no socios de forma constante. Aun más, reconocen el gran atractivo de estas personas por la cualificación que aportarían a los órganos. Fundamentalmente, entre las posibles alternativas, podrían revestir esta condición antiguos padres como sujetos más idóneos, dada la experiencia, formación y conocimientos adquirida por estos, que sin lugar a dudas transmitirían a los demás miembros.

\section{Régimen Legal}

1. Si tenemos en consideración las Leyes de Cooperativas, inicialmente estos cuerpos legales parten de la base, que para ser consejero se goce de la condición de socio. Sin embargo tanto la LGC como LCE contemplan la posibilidad de que sujetos no socios puedan ser igualmente consejeros.

Consideramos adecuado recoger aquí, literalmente los párrafos segundos de los artículos 34 LGC y 41 de LCE con el fin de facilitar al lector de forma sucinta y clara el estudio de estos preceptos.

19 Vid, artículo 103 LGC, idem, artículo 106 y ss LCE. Queda claro que a las Cooperativas de Enseñanza, en las cuales los padres sean asociados se les aplicará la regulación correspondiente a las Cooperativas de Consumo, mientras que a las de profesores y personal no docente será la normativa sobre Cooperativas de trabajo asociado. 
Teniendo en cuenta la Ley Estatal, la denominada «Ley General de Cooperativas» (L.G.C ):

\section{Artículo 34.2. Elección:}

Los Estatutos podrán admitir el nombramiento como consejeros de personas cualificadas y expertas que no ostenten la condición de socios en numero que no exceda de un tercio del total y que en ningún caso podrán ser nombrados Presidente ni Vicepresidente. Salvo en tal supuesto y el previsto en el artículo anterior, tan sólo podrán ser elegidos como consejeros quienes ostenten la condición de socios de la Cooperativa.

En cuanto a la Ley de la Comunidad del País Vasco, calificada como «Ley de Cooperativas de Euskadi» (L.C.E ):

\section{Artículo 41.2. Elección de los administradores:}

... En el Consejo Rector, una cuarta parte de sus miembros podrá ser elegida entre personas no socios, salvo prohibición expresa de los Estatutos.

2. Como bien podemos observar, ya señalado con anterioridad, tanto la Ley Estatal como la Comunitaria, posibilitan que una Sociedad Cooperativa designe a personas no socios para integrar u ocupar un cargo en el órgano de gobierno, esto es, que se integren en el mismo Consejo Rector.

A este respecto, debemos subrayar que ha habido una evolución en la normativa. Concretamente, la idea de que no socios puedan ocupar un cargo en los órganos sociales, es una de las novedades que podemos observar dentro de la Ley Estatal de Cooperativas vigente del año 1999, que ha introducido con respecto a la legislación anterior datada en $1987^{20}$. Esta practica o posibilidad se presentó como novedad y aspecto positivo dentro de la Ley del año 199921. Eso sí,

20 Referencia; 3/1987, 2 de abril Ley General de Cooperativas.

21 En este sentido, Rodrigo UrIA, Aurelio MenÉndez y Mercedes Vérgez. La Ley de 1987 no excluía para la Sociedad Cooperativa la posibilidad, siempre útil, de recurrir a una gestión técnica y profesionalizada, quien no perteneciera a la sociedad (admitiendo que se pueda encomendar la dirección personalizada de la empresa cooperativa a un Director o Gerente cuyas facultades sólo podrían alcanzar al tráfico empresarial ordinario) $\rightarrow$ la Ley actual va más allá y reconoce que los Estatutos podrán admitir el nombramiento como consejeros de personas cualificadas y expertos aunque no ostenten la condición de socios, siempre que en ningún caso su número exceda de un tercio del total de miembros del Consejo, y siempre que no sean nombrados Presidentes ni Vicepresidente... 
deberá mediar la necesaria previsión estatutaria al respecto, es decir, los Estatutos de cada cooperativa tienen que contemplar este criterio de elección. Además los artículos regulan unos limites, en cuanto al número de dichos administradores no socios se refiere, precisamente esta cantidad, no puede exceder de una tercera parte en lo que a la ley Estatal se refiere y una cuarta parte en el caso de la Ley Comunitaria22.

3. Los beneficios de implantar la figura del Consejero Independiente en las Cooperativas

1. Según las consultas llevadas a cabo a expertos en la materia, como ha quedado reflejado en el epígrafe anterior, parece que no confían demasiado en esta figura.

Por el contrario, nosotros mantenemos una postura optimista e incidimos en los beneficios que dicha figura aportaría en el supuesto de su nombramiento.

Como hemos reiterado en el transcurso de este trabajo los Códigos de Buen Gobierno destacan la importancia de esta clase de consejeros, concretamente, el Código Olivencia al analizar la composición del Consejo de Administración de las Sociedades Cotizadas, (Consejo Rector en Cooperativas), resalta en particular la figura del Consejero Independiente, recomendando su entrada en el órgano de gobierno.

Nosotros, siguiendo la fórmula utilizada por estos Códigos del buen hacer vamos más allá y también recomendamos, puesto que las leyes lo tienen en cuenta y así lo admiten, la posible inclusión de no socios dentro del Consejo Rector de las Sociedades Cooperativas.

2. No conviene olvidar lo que la Comisión Especial expuso en 1998, subrayando que; «la entrada de consejeros en el órgano de gobierno incrementará su representatividad, ampliará sus puntos de vista y elevará la disposición y la capacidad del consejo para desarrollar con eficiencia la función de supervisión». Estamos de acuerdo con lo propuesto por los Códigos de Buen Gobierno, quienes al tratar sobre los Consejeros Independientes, manifiestan que esta figura aporta un

22 En esta línea, en el manual de Morillas Jarillo/Feliu ReY, Curso de Cooperativas, precisa y refleja algunos apuntes sobre las diferencias que hacen que cada Ley que conviven en el estado diverja de las demás. Para mayor información véase pp. 296 y 297. 
equilibrio en la composición del Consejo. Nuestra postura se debe a que, podemos considerar al Consejero Independiente como una persona preparada, capacitada profesionalmente, que puede aportar buen juicio y facilitar relaciones al Consejo y consecuentemente también a la empresa.

Precisamente, los artículos arriba desarrollados emplean términos o palabras tales como: «cualificadas y expertas» al hablar sobre estas personas no socios; de igual modo el Informe Olivencia utiliza conceptos al tratar el tema de los Consejeros Independientes, por ejemplo entre otros cita, el prestigio profesional de estos sujetos, y cómo no, de expresiones tan importantes como que deben de ser independientes. Con esta última idea queremos dar a conocer que nos encontramos delante de una figura particular o singular, ya que lo característico de estos consejeros o para nuestro caso no socios, es la exención de dependencia, es decir, que no están sometidos a nadie, rechazando, por tanto, toda sujeción y sosteniendo así sus derechos u opiniones personales.

3. Asimismo no debemos olvidar, que nos movemos, para éste nuestro estudio, entre Sociedades Cooperativas. Entendemos por Cooperativa, al grupo humano constituido con fines productivos aunando trabajo y capital en unas mismas manos. Estas sociedades, sobresalen y distinguen, por su fuerte carácter democrático. Por todos es conocido, este principio que singulariza a la entidad Cooperativa respecto de los demás modelos de empresa. Considerando esto, podemos razonar que el incluir miembros no socios dentro del órgano de gobierno, reafirma más si cabe su naturaleza democrática.

4. En nuestra opinión, es valioso incorporar consejeros que sean externos dentro del Consejo Rector. Hemos repetido reiteradamente en el desarrollo de este trabajo, que lo que distingue ha estos sujetos es su independencia, por ello, siendo personas no vinculadas con la Cooperativa, no podemos poner en duda, que aportarán más transparencia, esto trae consigo que el Consejo funcione con mayor neutralidad. El miembro no socio, aporta ideas nuevas y algo ajenas, por decirlo de alguna manera, es decir, ideas que vienen dadas desde fuera de lo que es el entorno de la Cooperativa. Esto en definitiva viene a decir, que este sujeto analizará desde fuera, lo que desde dentro no puede estar tan claro. Por lo tanto, es obvio que la incorporación de los denominados consejeros externos independiente o personas no socias en el Consejo de las Sociedades Cooperativas, aportará grandes beneficios, dado que facilitan y transmiten diferentes puntos de vista, 
que serán de gran utilidad para el desempeño de las actividades y funciones del órgano de gobierno.

Igualmente, es de mencionar el gran beneficio que acarrea el dotarse de personas con una gran formación empresarial o académica para fijar la composición del Consejo Rector, puesto que ofrecen y proporcionan aire fresco a este órgano. Por si esto fuera poco, como hemos apuntado previamente, contribuyen positivamente aportando reflexiones o conocimientos siempre valiosos y enriquecedores para la Sociedad Cooperativa.

Además, entendemos, que su participación debe ser significativa, trascendente, para el buen gobierno de la empresa. Mas aún, pensamos que es importante que esta figura exista y que sea capaz de trabajar en colaboración con sus colegas ejecutivos y poder hacer así uso, de su objetividad e independencia de juicio cuando sea necesario. En general lo que cabe esperar de estos Consejeros o personas no socias, son sus opiniones y juicios neutrales, aportaciones cualificadas y relaciones de interés.

5. Dicho esto, podemos arriesgarnos a señalar que la entrada de personas no socios como miembros del Consejo Rector, puede percibirse como algo innovador desde el punto de vista de los trabajadores que realizan tareas para la Sociedad Cooperativa. Nadie puede negar, que estos consejeros ofrecerán representación a todos los diferentes agentes que operen en la Cooperativa. Sin lugar a dudas, esto es beneficioso no sólo para los demás miembros que compongan el órgano de gobierno, sino también y en especial, será positivo para los trabajadores. Pensamos, que con la incorporación de los no socios, los trabajadores se sentirán mayormente identificados y representados. Desde la posición o situación de un trabajador, el cual no forma parte, ni se encuentra implicado en la gestión de la sociedad, puede ver en la figura del Consejero Independiente o en la persona no socia, alguien no vinculado, autónomo, es decir, independiente y con plena libertad de criterios. A lo mejor es aventurado decirlo, pero puede que el trabajador vea su persona en igualdad de condiciones y sin diferencias, en ese consejero no socio.

\section{Conclusiones}

1. A modo de conclusión, debemos expresar que no se puede discutir, que la incorporación de estos consejeros aporta «frescura», 
por decirlo de algún modo, y por qué no, también un grado de independencia. A nuestro parecer, es beneficiosa esta incorporación, ya que ofrece equilibrio y mayor eficacia al Consejo Rector. Más aún, igual de ventajoso se refleja para el Gobierno Corporativo, por todos sabido, que últimamente cada vez son mayores las controversias surgidas por la falta de una adecuada estructura orgánica. Es incuestionable que los no socios contribuyen en ideas nuevas para la gestión del órgano, necesitado de estabilidad pero a la vez de cambios.

Por tanto, nada impide la recomendación de estos Consejeros Independientes o no socios, puesto que aportan riqueza a la hora de querer obtener un órgano de gobierno más competente y capaz de llevar la gestión de la Sociedad Cooperativa de forma eficaz.

2. Más aún, hay que tener en cuenta que no son pocos los trabajos y estudios realizados acerca de esta materia, prueba de ello son los Informes Éticos o de Buen Gobierno. Estos, han dado mucha importancia ha esos sujetos, apostando por ellos y aportándoles gran confianza. Nosotros también somos de los que apuestan por mirar en positivo y con optimismo la integración de esta figura. Además, no debemos olvidar que personas expertas en materia de Cooperativas, no descartan en absoluto esta posibilidad. Como bien hemos reflejado anteriormente, un ejemplo, es la situación de las Cooperativas de Enseñanza, que necesitan y consideran valiosa esta opción. He aquí la prueba que apoya y ratifica nuestra afirmación. La constatación de esta situación es también una ocasión más para reivindicar la opción del nombramiento como consejero de una persona no socia.

3. Se puede concluir sosteniendo, que estamos ante una figura útil para las Cooperativas, como hemos querido e intentado reiterar a lo largo de este trabajo. Se trata de una noción que no ha sido asumida con suficiente seriedad por las Sociedades Cooperativas, en definitiva, una figura poco respaldada y con escasa experiencia. Ahora bien, las exigencias en la vida diaria de una Cooperativa parecen ser otras, por tanto, no parece lógico dejar de lado esta posibilidad.

\section{Bibliografía}

Gobierno de las sociedades cotizadas, Gaudencio Esteban Velasco (Coordinador). «Colección Garrigues \& Andersen» Marcial Pons, Ediciones Jurídicas y Sociales S.A. Madrid 1999 Barcelona. 
Curso de Cooperativas. María Jose Morillas Jarillo, Manuel Ignacio Feliú ReY. Editorial Tecnos, 2002.

Derecho Mercantil. Rodrigo URIA. Marcial Pons, Ediciones Jurídicas y Sociales S.A. Madrid 1999.

Código Olivencia. (Código Olivencia: elaborado por la Comisión Especial para el estudio de un código ético de los consejeros de administración de las Sociedades Cotizadas de 26 de febrero de 1998).

Informe Aldama. (Informe Aldama: Informe de la Comisión Especial para el Fomento de la transparencia y seguridad en los mercados y en las Sociedades Cotizadas, publicado el 8 de enero de 2003).

Código de Comercio. Aranzadi Editorial. Ley 27/1999 de 16 julio sobre Cooperativas.

Ley 4/1993 de Cooperativas de Euskadi. Página de Internet: www.noticiasjuridicas.com 